\title{
A ENGENHARIA BRASILEIRA CONTEMPORÂNEA E A CONTRIBUIÇÃO DAS MULHERES NAS MUDANÇAS RECENTES DO CAMPO PROFISSIONAL ${ }^{1}$
}

Maria Rosa Lombardi*

Este artigo discute as mudanças que vêm ocorrendo no campo de conhecimento e de trabalho da Engenharia no Brasil contemporâneo e o papel que as mulheres tiveram e continuam tendo nesse processo. Aqui se adota como foco privilegiado de análise a perspectiva das relações sociais de sexo que se estabelecem entre homens e mulheres no campo profissional e nos espaços de formação de engenheiros. Essa abordagem teórica identifica uma tensão entre o grupo de homens e o grupo de mulheres que se revela permanente quando se trata do trabalho e da sua divisão social. Nesse sentido, as relações sociais de sexo e a divisão sexual do trabalho são indissociáveis e os princípios de separação e hierarquização que a organizam são válidos para todas as sociedades conhecidas e costumam ser legitimados por uma ideologia "naturalista', a qual compreende que a divisão sexual do trabalho está inscrita na ordem natural da sociedade e assim deve permanecer, sendo, portanto, imutável (KÉRGOAT, 1998) . As relações sociais entre o grupo de homens e o de mulheres, ao contrário, não se fundam em causas biológicas. Elas são construções sociais e assumem roupagens diversas em diferentes espaços geográficos e em

* Mestre e doutora em Educação pela Universidade Estadual de Campinas e doutora em Relações de Gênero, Trabalho e Profissões pelo Centre National de Recherches Scientifiques (França). Pesquisadora da Fundação Carlos Chagas. (mlombard@fcc.org.br)

1 O artigo apresenta resultados parciais de tese de doutorado denominada "Perseverança e resistência: a engenharia como profissão feminina”, defendida em fevereiro de 2005, junto à Faculdade de Educação da UNICAMP- Universidade Estadual de Campinas, São Paulo, Brasil. 
diferentes épocas, ou seja, elas não são imutáveis, alterando-se no tempo e no espaço. As relações sociais de sexo estruturam todo o campo social e são transversais à totalidade desse campo, por isso Kérgoat (2000) as considera como um "paradigma das relações de dominação". Considerando o princípio preconizado nesse enfoque conceitual como fio condutor da análise, entendeu-se, assim, que as relações sociais de sexo que perpassam a área profissional da engenharia repousam, em primeiro lugar, sobre uma relação hierarquizada entre homens e mulheres, tratando-se de uma relação de dominação e de poder do grupo de engenheiros do sexo masculino sobre o grupo de engenheiras.

Seguindo essa perspectiva, o artigo abordará a questão considerando duas dimensões de análise, quais sejam, a identificação da evolução da presença feminina, sobretudo nos espaços de formação profissional, através da análise de dados estatísticos sobre matrículas e conclusões em cursos de graduação em Engenharia e a discussão dos padrões de gênero presentes no ambiente de algumas das mais tradicionais e prestigiadas escolas de engenheiros do País, em algumas áreas de trabalho e sua evolução recente. Para dimensionar a formação universitária dos engenheiros no País e a evolução da presença feminina dentro dela, recorreu-se aos dados oficiais do Censo da Educação Superior do MEC- Ministério da Educação, realizado pelo seu instituto de pesquisas, o INEP - Instituto Nacional de Estudos e Pesquisas Educacionais Anísio Teixeira² ${ }^{2}$ O período considerado

2 O Censo da Educação Superior coleta anualmente uma série de dados sobre esse nível de ensino no país, entre os quais as formas de organização acadêmica e categorias administrativas das instituições de ensino, os cursos de graduação presenciais e à distância em todas as áreas do conhecimento, as vagas oferecidas, os candidatos que as disputam, os ingressantes pelo vestibular e por outras modalidades segundo faixa etária e sexo, os concluintes, os docentes e sua qualificação, as atividades de extensão realizadas pelas instituições. A resposta ao Censo é obrigatória para todas as instituições de ensino superior ( IES) que, até o mês de outubro de cada ano tinham pelo menos um curso de graduação em funcionamento, isto é, que tenham realizado processo seletivo até aquela data. As IES respondem a um extenso e detalhado questionário pela Internet, o qual deve ser entregue ao MEC no começo do ano seguinte ( p.ex., Censo de 2002 deve ser entregue até início de 2003). As IES, dessa forma, se responsabilizam pelas informações prestadas e, mesmo que em tese estejam sujeitas à verificação do MEC, não há certeza de que os dados passem por uma fase de crítica antes de serem processados no INEP . O Censo da Educação Superior, portanto, consolida as informações registradas pelas IES sobre o seu funcionamento e produtividade a partir de parâmetros de padronização e conceituação definidos pelo MEC ( www.inep.gov.br; censo da educação superior). 
foi o mais recente, de 1990 a 2002, em função de limitações apresentadas pela própria base de dados ${ }^{3}$. A discussão dos padrões de gênero presentes nos campos de conhecimento e profissional baseou-se no ponto de vista dos sujeitos que os vivenciam atualmente ou os vivenciaram em passado recente, recolhidos em entrevistas pessoais realizadas com engenheiros, engenheiras, estudantes de Engenharia e dirigentes sindicais, no período de março a junho de 2004, no Estado de São Paulo ${ }^{4}$.

\section{OS ANOS 80 E 90: TEMPOS DE CRISE NO EMPREGO E DE TRANSFORMAÇÃO NO CAMPO DE TRABALHO E NO GRUPO PROFISSIONAL}

Pelo menos três ordens de fatores contribuíram para as mudanças que aconteceram no campo de trabalho da engenharia e na categoria profissional dos engenheiros, nos anos 80 e 90, quais sejam: a consolidação do aumento da escolaridade das brasileiras - processo em curso desde a década de 70- e sua repercussão na ampliação das escolhas profissionais femininas; a expansão do número de escolas e de cursos de Engenharia

3 O principal problema enfrentado para a construção de séries longitudinais que mostrassem a evolução das matrículas e conclusões em cursos de engenharia foi, justamente, a descontinuidade temporal da apresentação dos dados cruzados pela variável sexo. Esse cruzamento que existia na Sinopses do Ensino Superior até final da década de 60, deixou de ser publicado durante os anos 70 e 80, voltando a constar da divulgação de resultados somente a partir de 1990, via Internet. Face a essa circunstância, tornou-se impossível acompanhar a progressão das conclusões femininas em cursos de engenharia, justamente num período onde as mulheres começaram a procurar a formação em nível superior em maior número, a partir dos anos 70.

4 A pesquisa de campo compôs-se de 33 entrevistas no total, 26 com mulheres e 7 com homens, realizadas em duas etapas. A primeira fase, de caráter exploratório, composta por 8 entrevistas com mulheres, engenheiras e dirigentes sindicais, desenvolveu-se na França, entre os meses de março e maio de 2003, durante estágio de doutorado realizado em Paris. As demais 25 entrevistas foram realizadas durante a pesquisa de campo no Brasil, sediada no Estado de São Paulo. A amostra da pesquisa de campo brasileira foi composta por indicações de profissionais que partiram dos próprios entrevistados, iniciando-se o processo de "amostra intencional" com uma engenheira formada pela Escola Politécnica da Universidade de São Paulo. Conscientes da importância da escola de engenharia cursada na vida profissional futura e conscientes também da impossibilidade de contemplar numa amostra reduzida o extenso e diversificado universo de escolas de engenheiros, optou-se por concentrar o maior número de entrevistas (68\%) entre formados e estudantes numa da mais prestigiadas e tradicionais escolas de engenheiros do país, a Escola Politécnica da Universidade de São Paulo. 
e a intensificação da especialização no sistema de ensino, que, além ter produzido efeitos sobre o emprego e os rendimentos da categoria, acentuou sua segmentação interna e, finalmente, as profundas mudanças que afetaram a economia e o mercado de trabalho nacionais naquelas duas décadas e seus reflexos nos empregos e nos rendimentos dos engenheiros .

\section{Mulheres, educação superior e formação em Engenharia}

Vários estudos têm reiteradamente mostrado que, a partir dos anos 80 , juntamente com a contínua expansão da ocupação feminina, o perfil dessa força de trabalho vem se alterando, pois diferentemente do que se verificava até a década de 70 , hoje a maioria das trabalhadoras é mais velha, casada e tem filhos. Além disso, nesse último quarto de século, se desenharam e se consolidaram duas outras tendências: verificou-se importante queda na taxa de fecundidade das brasileiras, o que influenciou no tamanho das famílias, hoje muito menores do que no passado e o aumento do número de famílias chefiadas por mulheres (BRUSCHINI e LOMBARDI 1996; GUIMARÃES, 2001). Talvez, porém, a mudança mais importante no perfil das trabalhadoras brasileiras que se esboçou e se concretizou nesses últimos 25 anos, tenha sido o aumento do seu nível de escolaridade. Em 1999, na população em geral, havia um equilíbrio na participação de cada sexo (cerca de 50\%) entre as pessoas que haviam concluído o ensino fundamental (oito anos de estudo), o qual será rompido em favor das mulheres do ensino médio em diante: elas representavam 55\% dos que tinham entre 9 e 11 anos de estudo e 54\% dos que tinham 12 anos de estudo (Bruschini e Lombardi 2003). Considerando especificamente o ensino superior, as mulheres representavam $59,7 \%$ dos concluintes em 1990, 61,7\% em 2000 e 62,9\% em 2002, segundo informa o MEC (FCC 1998).

Ao analisar as escolhas femininas nesse nível de ensino desde meados da década de 90 , verifica-se um movimento em duas direções. De um lado, há a continuação da preferência por áreas de conhecimento tradicionalmente feminizadas,- Saúde , Serviços, Educação, Ciências Sociais, Negócios e Direito-, ainda que algumas delas venham registrando cada vez menor interesse das jovens. De outro, vem se dando uma ampliação desse 
leque de opções para outras áreas: a preferência feminina por cursos em Agricultura e Veterinária cresceu de 37\% para 40\%, entre 1995 e 2002; no mesmo período manteve-se em torno de $1 / 4$ o ingresso das jovens nos cursos de Engenharia, Produção e Construção (FCC 1998; Série Histórica: Mulheres, Educação e Trabalho).

Voltando o olhar especificamente para a formação dos engenheiros, observa-se que durante toda a década de 90 e nos primeiros anos do novo milênio, veio crescendo lenta e continuamente o número de mulheres que ingressaram nos cursos de engenharia no Brasil. Como mostra a tabela 1, se em 1991 a parcela feminina no conjunto de matrículas em cursos de engenharia era $16,4 \%$, ela cresce para 19,5\% em 1995, tem uma ligeira diminuição nos anos seguintes e atinge 20\% em 2002. Essa performance positiva dependeu também do menor crescimento das matrículas masculinas, pois enquanto sua variação no período mostra um crescimento de $42 \%$, o acréscimo nas matrículas femininas foi de 84\%, ou o dobro. Esses números permitem concluir que a engenharia está incluída nas escolhas profissionais das mulheres, embora, como se viu, esse processo venha evoluindo lentamente.

Não se pode deixar de remarcar a acentuação do crescimento das matrículas em cursos de engenharia entre 1999 e 2002: o MEC registrou o acréscimo de 48.380 matrículas, 14.034 femininas e 34.346, masculinas. A taxa de crescimento tomada naqueles quatro anos demonstra, ainda mais claramente, o maior crescimento das matrículas femininas frente às masculinas : enquanto a matrícula masculina cresceu $26 \%$, a feminina cresceu 50\%. Em outras palavras, considerando o conjunto da década de 90 e os dois primeiros anos do novo milênio, mais da metade do crescimento das matrículas de ambos os sexos em cursos de Engenharia no País se deu entre 1999 e 2002.

\section{Tabela 1: Matrículas em cursos de Engenharia segundo o sexo* Brasil 1991-2002}

\begin{tabular}{c|c|c|c|c}
\hline Anos & Total & Mulheres & Homens & $\begin{array}{c}\text { Parcela feminina } \\
(\%)\end{array}$ \\
\hline 1991 & 140308 & 22953 & 117355 & 16,4
\end{tabular}


revista tecnologia e sociedade

\begin{tabular}{c|c|c|c|c} 
Anos & Total & Mulheres & Homens & Parcela feminina \\
1992 & 138037 & 23268 & 114769 & $\mathbf{( \% )}$ \\
1993 & 138502 & 24117 & 114385 & 17,4 \\
1994 & 140169 & 25765 & 114404 & 18,4 \\
1995 & 143017 & 27541 & 115476 & 19,3 \\
1996 & 146376 & 25582 & 120794 & 17,5 \\
1997 & 144891 & 26079 & 118812 & 18,0 \\
1998 & 150217 & 28454 & 121763 & 18,9 \\
1999 & 160779 & 28112 & 132667 & 17,5 \\
2002 & 209159 & 42146 & 167013 & 20,1 \\
\hline Variação no & $\mathbf{4 9 , 1}$ & $\mathbf{8 3 , 6 \%}$ & $\mathbf{4 2 , 3}$ & - \\
periodo (\%) & & & & \\
\hline
\end{tabular}

Fonte: MEC/INEP; Censo do Ensino Superior. Tabulações especiais

* Inclusos Engenharia de Operação e Agrimensura; excluídos Arquitetura e Urbanismo e Geologia

\section{As mulheres, a expansão e a especialização do sistema de ensino de Engenharia}

Deve-se ressaltar que o crescimento das matrículas femininas na década de 90 se deu no bojo da democratização do ensino da Engenharia no País. Se o número de cursos de Engenharia vem crescendo desde a década de 60, a expansão mais expressiva aconteceu nos últimos doze anos, entre 1990 e 2002. Como informam dados oficiais do Ministério da Educação, o número de cursos $^{5}$ para engenheiros no País evoluiu de 98 em 1963, para 179 em 1968, para 313 em 1975, chegando em 1991 a 330 e, em 2002 , a 837.

Apenas na última década, portanto, o número de cursos de engenharia cresceu uma vez e meia. Como decorrência, a oferta de engenheiros formados acompanhou o mesmo movimento de expansão. Como informa a

5 Inclusive Engenharia de Operação e Agrimensura e exclusive Arquitetura e Urbanismo e Geologia. 
mesma fonte ${ }^{6}$, o número de concluintes em cursos de engenharia que era de 1.857 indivíduos em 1.963, sobe para 4.335 em 1.968, para 11.796 em 1974, para 13.026 em 1991, chegando a 19.886 no ano de 2002. Assim, no espaço de dez anos, entre 1991 e 2002, o número de engenheiros formados que saíram do sistema escolar aumentou $53 \%$ !

No caso dos engenheiros e de outros profissionais de nível superior, a segmentação interna à categoria profissional começa desde a escola e, no período analisado, os dados do MEC informam que a grande expansão dos cursos de Engenharia se deu no sistema de ensino privado, de onde, conseqüentemente, saíram as maiores proporções de formados. Além disso, o ensino de engenharia tradicionalmente tem se dado em período integral, mas as escolas particulares inauguraram os cursos noturnos na área: são elas que oferecem 93\% das vagas noturnas (Lombardi, 2005; Introdução, tabela 3). Com exceção de algumas tradicionais escolas de Engenharia particulares de reconhecida excelência, o ensino de melhor qualidade tende a se concentrar nas escolas públicas, normalmente em cursos ministrados em período integral. Como os mesmo dados indicaram, entretanto, a proporção desses formados no conjunto do sistema é reduzida ${ }^{7}$, podendose afirmar que dessas escolas saem os engenheiros que comporão a elite da categoria profissional.

Concomitantemente a esse processo de democratização do ensino, uma outra tendência se consolidou, a saber, a ampliação do leque de especialidades no ensino da Engenharia, através do desdobramento das antigas áreas ou da criação de especialidades novas. Isso contribuiu para a diversificação das escolhas de homens e mulheres, mas incidiu especialmente sobre as opções femininas que, até meados dos anos 90, se encontravam mais concentradas nas engenharias civil e química. Como demonstra a tabela 2, desde 1960 , no Brasil, as maiores proporções de mulheres graduadas em cursos de engenharia saíram da especialidade civil

6 Ministério da Educação/SEEC- Serviço de Estatística da Educação e Cultura; Sinopses Estatísticas do Ensino Superior, Rio de Janeiro, 1965;1969; Brasília, 1977; MEC/INEP- Instituto Nacional de Pesquisas Educacionais Anísio Teixeira- Censo do Ensino Superior 1992 e 2002 [www.inep.gov. br]. Tabulações especiais.

7 Por exemplo, no Estado de São Paulo, em 2003, apenas 21\% do total de formados em Engenharia saíram de escolas públicas e $22 \%$ das mulheres. 
(65\%), área que também congregava a maioria dos concluintes do sexo masculino naquele ano. A concentração em civil está inscrita na própria história do ensino de engenharia no Brasil, pois foram dessa área os primeiros cursos oferecidos. Eles congregavam várias outras áreas que, posteriormente, se desagregaram. Um exemplo desse "guarda-chuva" que então era a Engenharia Civil é o caso específico da Escola de Minas de Ouro Preto, que mantinha um curso denominado Engenharia Civil, de Minas e Metalurgia. Quanto à Engenharia Química, desde os primórdios, parece ter despertado o interesse das mulheres.

\section{Tabela 2: Proporções de concluintes * por sexo nas Engenharias Civil e Química Brasil 1960, 1990, 1995, 2002}

\begin{tabular}{r|c|c|c|c|c|c|c|c}
\hline \multirow{2}{*}{ Anos } & \multicolumn{3}{|l|}{ Totais } & \multicolumn{3}{l|}{ Civil } & Química & Outras \\
\cline { 2 - 9 } & Hs & Ms & Hs & Ms & Hs & Ms & Hs & Ms \\
\hline 1960 NA & 1477 & 17 & 879 & 11 & 67 & 4 & 531 & 2 \\
$\%$ & 100 & 100 & 60 & 65 & 4 & 24 & 36 & 11 \\
\hline $\mathbf{1 9 9 0}$ NA & 9980 & 1630 & 2790 & 718 & 601 & 243 & 6589 & 669 \\
$\%$ & 100 & 100 & 28 & 44 & 6 & 15 & 66 & 41 \\
\hline $\mathbf{1 9 9 5}$ NA & 12138 & 3277 & 3492 & 1365 & 611 & 509 & 8035 & 1403 \\
$\%$ & 100 & 100 & 29 & 42 & 5 & 16 & 66 & 43 \\
\hline $\mathbf{2 0 0 2}$ NA & 15327 & 4559 & 4061 & 1362 & 565 & 470 & 10701 & 2727 \\
$\%$ & 100 & 100 & 26 & 30 & 4 & 10 & 70 & 60 \\
\hline
\end{tabular}

Fonte: MEC/SEEC Sinopse estatística do ensino superior(1960);

MEC/INEP Censo da educação superior (1990-2002)

* exceto Agronomia e Geologia

No processo de especialização das Engenharias que acompanhou o desenvolvimento econômico e o processo de industrialização do País, ocorreu o desmembramento da área civil em outras especialidades que se constituíram em cursos específicos. Essa dinâmica é sugerida pela mesma tabela 2: 30 anos depois, em 1990, enquanto a proporção de mulheres 
concluintes em Engenharia Civil permanecia importante, embora bem menor (44\%), o mesmo acontecendo com Química (15\%), aumentava a porcentagem das formadas em "outras especialidades". Se em 1995, cenário muito semelhante se desenhava, em 2002 ele irá se alterar profundamente: pela primeira vez, nos últimos 42 anos, as proporções de formadas em Civil e Química (40\%) será menor do que as formadas em outras especialidades (60\%). Despontam como outras opões que interessam às mulheres: Alimentos (10\% das conclusões), Elétrica $(8,5 \%)$, Florestal (4\%), Produção (3\%), Mecânica (3\%), Mecatrônica (1,5\%), Materiais, Produção Mecânica, Produção Industrial Produção Elétrica, Sanitária (1,4\% cada uma), Computação (1,3\%), Ambiental (1\%), Pesca e Agrícola (0,9\% cada) (Lombardi, 2005; Anexo 2, tabela C). Confirmando a menor concentração das escolhas masculinas frente às femininas, já em 1960, $1 / 3$ deles (mas apenas $11 \%$ delas) haviam cursado outras especialidades. Em 1990, 2/3 dos formados - e apenas 41\% das formadas- cursaram outras especialidades, proporção que atingiu 70\% em 2002.

Esse padrão feminino mais concentrado das escolhas das especialidades desvela duas faces do mesmo fenômeno. De um lado, como a análise das estatísticas de emprego revelaram, as escolhas femininas encontraram ressonância no mercado de trabalho. Advêm da Civil as maiores porcentagens de empregos para engenheiras (e para engenheiros) durante toda a década de 90 : em 2002, $32 \%$ dos postos de trabalho formais eram para engenheiras civis (essa especialidade absorveu 27\% dos engenheiros). Quanto à Química, quando se compara o seu peso na geração de empregos por sexo, entre as engenheiras ele é significativamente superior do que entre os engenheiros $(6,2 \% \text { e } 3,7 \% \text {, respectivamente, em 2002) })^{8}$. Ao mesmo tempo, a maior concentração das mulheres naquelas duas especialidades é reveladora da segregação que atingiu e ainda atinge as mulheres no campo de estudos e de trabalho da engenharia. Nesse sentido, a recente ampliação e diversificação na oferta de especialidades parece ter favorecido a inclusão das mulheres na profissão, oferecendo-lhes possibilidades de inserção em novos campos de atuação profissional, justamente num período em que

8 Fonte dos dados: Ministério do Trabalho e Emprego, RAIS- Relação Anual de Informações Sociais2002; CD ROM 
elas acederam em número crescente às escolas de engenharia, como se demonstrou.

Giannini (2003), Guevara (2002) e Rodrigues (2004) em seus respectivos países, Itália, México e Portugal, concluem que a segmentação interna das especialidades da Engenharia e o alargamento do campo de atividades profissionais dos engenheiros - cada vez menos centrado na produção industrial e no "chão-de-fábrica" e cada vez mais voltado para atividades de prestação de serviços-, favoreceram e estimularam o ingresso das mulheres. Giannini (op.cit) pondera que na Itália, naquelas especialidades mais ligadas à indústria, as estratégias profissionais dos engenheiros tendem a monopolizar as possibilidades de trabalho para os homens, enquanto que em outras surgidas recentemente e ainda sem um campo de atuação claramente delimitado ou ainda naquelas em que o trabalho da Engenharia vem sofrendo transformações, a exclusão das mulheres é menos drástica. Observando a tendência feminina à diversificação da escolha das especialidades e dando crédito a esta interpretação proveniente de outros países, poder-se-ia concluir que as engenheiras brasileiras têm sido bemsucedidas na ocupação dos espaços profissionais novos, particularmente a partir dos últimos anos da década de 90.

\section{Engenheiros e engenheiras, as mudanças econômicas e no mercado de trabalho}

As mesmas décadas de 80 e 90 no Brasil foram marcadas por importantes transformações de ordem econômica que alteraram a estrutura do mercado de trabalho nacional, resultando no aumento do desemprego, no crescimento de formas mais precárias de inserção laboral e na correspondente redução do mercado formal de empregos, na queda dos rendimentos do trabalho para todos os brasileiros. A desaceleração do crescimento econômico que vinha se registrando desde o final da década de 70 , mas que se aprofundou nos anos 90 , a retração da atividade industrial e a intensificação dos processos de reestruturação organizacional e produtiva das empresas industriais, a política de enxugamento de quadros na administração pública direta e indireta, a política de privatização das empresas estatais, a diminuição da capacidade de investimento do Estado, 
seja como contratante de obras públicas de infra-estrutura, seja como fomentador do desenvolvimento industrial, foram alguns dos fatores que influenciaram na redução do emprego formal para engenheiros.

Num ambiente economicamente instável, o considerável incremento de engenheiros formados lançados no mercado, oriundos majoritariamente das novas escolas de Engenharia criadas pelo setor privado, cuja qualidade do ensino, em muitos casos, deixa a desejar, certamente contribuiu para a deterioração das condições de emprego e remuneração de toda a categoria e para a intensificando da sua segmentação interna.

De fato, sob essa conjuntura que aliou mudanças econômicas e alterações que aconteceram no corpo do grupo profissional, os engenheiros sofreram importante redução dos empregos formalizados, bem como queda nos seus rendimentos mensais médios. No que tange aos empregos com algum tipo de contrato formalizado, houve uma acentuada perda de postos de trabalho, iniciada nos anos 90: entre 1990 e 1998, houve uma perda de 48247 postos de trabalho para engenheiros no país, 38576 dos quais masculinos e 9671 , femininos. No entanto, observando-se a variação dos empregos no período segundo o sexo, verifica-se que os cortes de postos de trabalho foram relativamente maiores entre as engenheiras. Assim, se no conjunto de empregos para a categoria, entre 1990 e 1998, houve um crescimento negativo dos empregos de $-28 \%$, a variação encontrada para os postos de trabalho femininos foi de $-38,3 \%$ e para os masculinos, $-26,2 \%$. A partir de 1999 , a tendência negativa se inverte e se inicia uma lenta recuperação do emprego, a qual perdurará até o final 2002. Neste ano, em suma, o Ministério do Trabalho e Emprego computou 139.287 empregos para engenheiros no País, 119.396 masculinos e 19.891 femininos (LOMBARDI, 2005; capítulo 2).

Em termos de remuneração as perdas também foram importantes. A dos homens tendeu a crescer até 1995, quando atingiu a média máxima de 25 salários-mínimos (SM) mensais, decrescendo a seguir até atingir o menor patamar em 2002, ou 19,23 SM. Por outro lado, o rendimento feminino foi crescente até 1998 quando atingiu seu maior nível, 16,41 SM, decaindo para 13,68 SM em 2002. Quanto à remuneração, portanto, repetem-se para as engenheiras o já bem conhecido padrão de gênero, segundo o 
qual o trabalho feminino recebe remuneração inferior ao masculino: naquele último ano, elas ganhavam, em média, $71 \%$ do que seus colegas do sexo masculino. Não se deve perder de vista, porém, que os salários femininos de fato não aumentaram e que os masculinos diminuíram significativamente, elevando aquela proporção, aparentemente favorável às mulheres.

\section{"AO NASCER UMA MENINA, DEUS PERGUNTARIA: VOCÊ QUER SER BONITA OU QUER SER ENGENHEIRA?”}

Os campos de conhecimento e de trabalho das engenharias, como se pôde constatar até aqui, mantêm-se predominantemente masculinos, em que pese a cada vez maior presença das mulheres nas escolas de Engenharia e no mundo do trabalho.

Segundo revelaram os(as) entrevistados(as) que trabalham como docentes, permanecem atuando nos ambientes escolares mecanismos de estigmatização do grupo de moças, ainda minoritário nas escolas de engenharia na maioria das especialidades. Relembre-se aqui a mais clássica das piadinha sobre as mulheres na Engenharia, devidamente adaptada para as alunas de cada escola: quando a menina nasce, Deus pergunta : "v. quer ser bonita ou quer ser engenheira?”. Essa piada atinge diretamente a feminilidade da mulher ao estabelecer um antagonismo entre a capacidade de atrair os homens associada à beleza e o exercício da profissão de engenheira. Em outros termos, reafirma a pretensa oposição entre os pólos corpo e mente, sensualidade e razão, sentimentos e intelecto, feminino e masculino. Trata-se de piada ou mexerico depreciativo utilizado pelo grupo masculino, o mais tradicionalmente estabelecido na Engenharia para procurar atemorizar ou afastar o grupo minoritário das mulheres das escolas e do campo de trabalho profissional.

Como explicam Elias e Scotson (2000) em todos as configurações "estabelecidos-outsiders", a blame gossip tem se mostrado uma arma eficaz nas mãos do grupo estabelecido, destinada a ferir, humilhar, estigmatizar os membros do grupo outsider e ao mesmo tempo assegurar a ascendência do primeiro grupo sobre esse último. As crenças e estereótipos

9 A dicotomia "outsiders- estabelecidos, ou "os de fora" e "os de dentro", contribui para o entendimento dos mecanismos pelos quais um grupo estigmatiza e exclui o outro numa dada configuração que 
que circulam nos grupos interdependentes de uma tal configuração tendem a se tornar rígidos com o passar do tempo no interior dos grupos mais coesos, como é o caso do grupo de estudantes de Engenharia do sexo masculino. E o mecanismo utilizado para cimentar um estereótipo como, no caso, a pretensa feiúra das estudantes de Engenharia é muito simples: são isolados da realidade os exemplos que venham comprová-lo ao mesmo tempo em que se ignoram aqueles que o contradizem. Os exemplos que reiteram o estereótipo passam, então, a ser rapidamente disseminados através das organizadas redes de relações do grupo estabelecido, em comitês, associações, locais de encontro etc. $\mathrm{E}$ a fofoca feita pelas pessoas reforça a coesão já existente no grupo masculino que, como todo grupo humano estreitamente unido, funciona como "uma sociedade de admiração mútua” (Elias e Scotson 2000, p.128), onde a idealização ou carisma do grupo é muito importante.

Se o aumento de mulheres nos cursos de Engenharia tem colaborado, de um lado, para amenizar as reações do grupo de rapazes à sua presença e, de outro, para diminuir a sensação delas serem "estranhas no ninho", os mecanismos de controle social destinados a garantir a masculinidade das Engenharias de um modo geral e de determinadas especialidades, em particular, continuam em ação, como é o caso das brincadeiras e piadinhas, conforme relata Júlio (engenheiro metalúrgico, 33 anos, formado na Poli/ USP em 1993), atualmente docente em escola de Engenharia bastante tradicional situada na região da Grande São Paulo. Nas suas palavras:

"Eu particularmente gosto de trabalhar com mulheres, mas as piadinhas jocosas são constantes, em tom de "vamos tentar colocar uma ameaça para não ter isso (concorrência)”...(as piadinhas) Tem de tudo.. É uma coisa do tipo, as meninas vão

ambos venham a construir. Como esclarece Elias (op.cit), na base dessa figuração "outsidersestabelecidos" está a disputa por poder e prestígio : o grupo estabelecido tem domínio das posições de poder e de prestígio da sua comunidade, associação, profissão, etc e procura afastar os outros, os "outsiders", dessas posições por meio da exclusão e da estigmatização . A coesão maior de um grupo em face do outro contribuiria para o seu excedente de poder ( reserva dos melhores cargos, posições sociais de maior poder, etc) e para excluir os membros dos outros grupos dessas posições. 
prá Química porque tem cozinha, vão aprender a cozinhar direitinho... sempre que se brincava com a Engenharia Civil, o pedreiro, então virava a pedreira, né?... era sempre tentando pegar o que tinha de jocoso com uma das engenharias, aumentava-se e piorava-se com uma menina no meio do caminho...Na metalurgia não ( tinha piadinhas), porque acho que em duas turmas anteriores e duas posteriores a gente não tinha meninas. Os colegas da mecânica, p.ex., acabavam com as meninas... eram poucas, 2 ou 3, com piadinhas, sempre com demérito. Interessante se ver isso até hoje, alguns grupos de projeto não pegam meninas ou são relutantes... se 10, 12\% da turma de engenheiros mecânicos é formada por meninas, porque não admiti-las na competição? (nacional e internacional de montagem de carros off-road pelos alunos). Isso eu sinto como preconceito do pessoal e não porque tem que ficar acordado até tarde, mexer com coisas mais brutas."

Esse engenheiro se refere a uma outra piadinha que associa a presença maior das mulheres na Engenharia com a desvalorização da profissão, reproduzida abaixo, embora discorde da relação entre os dois fenômenos. Na sua opinião, o que desvaloriza a profissão é ter um número de profissionais muito maior que a demanda atualmente, o que tende a rebaixar o salário. E a maioria desses profissionais é do sexo masculino, o que desautorizaria aquela relação. Ele reconhece que as piadinhas correntes nas escolas de Engenharia são mais a expressão de "um machismo mais irracional possível” do que uma questão de concorrência, pois há mais homens que mulheres concorrentes. Como, no entanto, a cada ano aumenta o número de meninas nos cursos de Engenharia, a piadinha abaixo, segundo Júlio, "rola solta":

"No início da Engenharia, o curso era desafiador, não se sabia o que ( como ) ia ser, então só quatrocentão fazia. $\mathrm{Na}$ seqüência , passou a ser um curso que dava muito dinheiro, passou a servalorizado, encheu de judeu. Passados mais alguns 
anos, percebeu-se que não era um curso pelo qual se podia ficar rico, mas era uma carreira estável, encheu de japonês, de orientais. Aí os cursos começaram a se desvalorizar no mercado, os valores (de remuneração) começaram a diminuir, encheu de mulher"

Como relembram Elias e Scotson (op.cit), as piadinhas, as fofocas, os mexericos são mecanismos de defesa utilizados por grupos que se sentem inseguros ou ameaçados, mesmo que essa ameaça seja apenas imaginária ou intuída. E os estudantes de Engenharia do sexo masculino têm sabido criar e fazer circular um bom arsenal de piadinhas, conforme o relato dos entrevistados. Mesmo que hoje as mulheres ainda não representem uma ameaça concreta, essas piadas também cumprem a função de alimentar 0 carisma grupal do grupo estabelecido e a desonra grupal atribuída, no caso, ao grupo de mulheres, fenômenos que aqueles autores designam como "gêmeos" e se expressam por formas estereotipadas de enaltecimento de um lado e de censura e calúnia, de outro.

Tendo em vista que determinadas especialidades da Engenharia, como a Mecânica e a Metalurgia continuam a se manter como áreas eminentemente masculinas até hoje, pode-se inferir que, entre outros mecanismos de controle social, o recurso às piadinhas que desmerecem as moças e as ridicularizam, atacando-lhes recorrente e diretamente a identidade de gênero cumpriu e continua cumprindo seu papel de intimidação. Isso contribuiu para alimentar a crença de que as escolas de Engenharia são ambientes hostis, de que a engenharia não é profissão para mulheres, enfim.

Em passado não muito distante - os anos 70- contudo, a intimidação das jovens por parte dos colegas do sexo masculino assumia contornos mais severos, conforme esclarece Aurélia, engenheira civil, hoje com 53 anos. Seu relato comprova como o ambiente das escolas de engenharia de uma forma geral -e o dos cursos de Engenharia Civil, em especial -foi se tornando mais receptivo às mulheres . Essa engenheira, formada em 1974 na USP, conta algumas situações por que passou como aluna e as estratégias defensivas postas em prática pelo coletivo de mulheres daquela escola . 
"Tem um machismo muito grande na dentro da Engenharia. Terrível, só que não é explícito, ele é implícito. Então, é difícil colocar em palavras o que está acontecendo. $P$. ex., quando entrei na escola, em 70...v. sentia, primeira coisa, logo que saiu a lista de aprovados, as veteranas entraram em contato com todas as calouras, eram 12 em 600, marcaram uma reunião. Nessa reunião elas já falaram que a gente ia enfrentar um monte de problemas e que inclusive tinha uma sala , o Departamento Feminino(DF), para a gente ficar tranqüila, pois lá os alunos não podiam entrar. $O$ número de mulheres era muito pequeno, então tinha o DF. Elas diziam, "olha, vs. vão ouvir um monte de piadinhas, a primeira é aquela "quando a mulher nasce, Deus pergunta se ela quer ser bonita ou politécnica”. Quando cheguei aqui, realmente fiquei apavorada porque parecia que o pessoal da Poli nunca tinha visto mulher na vida... . Eu entrava, ia correndo para o DF, até eu me enturmar com a classe. Aí eu podia ficar conversando com eles lá fora, já dava. Mas no primeiro mês, como eu chegava (de outra cidade, de ônibus) atrasada e as aulas eram no "cirquinho" e na minha classe só tinha eu de mulher, quando eu entrava atrasada os meninos assobiavam, mexiam comigo, era uma coisa constrangedora, horrorosa. Até eu descobrir que podia entrar por cima, ninguém ia me ver.. eu demorei (risos)... sabe, aquela fora do ninho..."

No tocante à relação aluna-professor, a memória dos(as) exalunos(as) da Poli não reteve episódios de assédio ou desrespeito. Mas, dentro do corpo docente das escolas de Engenharia, e particularmente entre os professores do sexo masculino, parecem existir piadinhas e brincadeiras que associam o maior número de mulheres numa turma ou numa disciplina à beleza física, simpatia ou juventude do professor, ou ainda, quando um professor seleciona mais moças que rapazes como bolsistas ou estagiários em um programa ou projeto de pesquisa, pode surgir a insinuação da existência de uma relação mais íntima entre ele e suas alunas. 
Aurélia, que atualmente é docente em uma escola de Engenharia, e Júlio, consideram que essas brincadeiras denotam falta de respeito pelas alunas e pelo professor envolvido também. Seus depoimentos:

“... existe um negócio que eu acho horrível, p.ex., os professores que dão aulas no $2^{\circ}$ ano já avisam os do $3^{\circ}$ quais são as meninas bonitas. Quando soube disso fiquei horrorizada .. é o tipo de coisinha tão impensável, soube disso de uns 7 , 8 anos prá cá, não sei se existia antes. Achei uma falta de respeito.... não é que eles vão paquerar as meninas, mas eles ficam.. "na minha classe tem tantas mulheres, na sua quantas tem?", "ele é bonzinho, as meninas gostam mais dele", "fulano tem sempre a sala cheia de mulheres porque ele é bonito, mais novo". Eu não acho que as meninas assistam aula com eles por causa disso, mas eles acham. Para mim é um desrespeito, um preconceito contra a mulher, eles não estão enxergando um aluno como outro qualquer, mas uma menina bonita que está assistindo aula "(Aurélia, 53 anos, engenheira civil e docente)

"Tenho alunos que trabalham comigo na iniciação científica. Os meus critérios são aptidão, empenho, bom histórico escolar porque vai trabalhar comigo. Não passa disso. Numa época, $60 \%$ dos alunos eram meninas e meus colegas professores, começou uma piadinha por trás. "o Júlio só contrata menina para trabalhar com ele”. Fui muito grosso, virei para trás e disse, "no laboratório nada é feito com os genitais, portanto qualquer um pode trabalhar". Os colegas diziam calma, calma... "Eu quero saber o que vs. estão insinuando com isso, que eu contrato mulher porque é mais bonitinha, é mais gostoso trabalhar com elas? Nada disso". Eu não era casado ainda, mas disse "tenho um relacionamento muito bom, muito estável e não é porque eu contratei uma mulher que vou ter um caso com ela". Depois disso nunca mais foi feita piada. Isso revela o perfil da coisa e a intenção de muita gente. 
Se alguém falou isso é porque contratam mulheres porque são bonitas ou porque têm intenções não profissionais. Isso me marcou muito”. (Júlio, 33 anos, engenheiro metalúrgico e docente)

A coesão do grupo majoritário de estudantes e professores do sexo masculino thes faculta poder para tentarem garantir futuras áreas de trabalho para si próprios desde a escola, utilizando, como vimos, de variadas estratégias conscientes ou inconscientes. Homens e mulheres que integram a configuração escola de Engenharia e as relações que se tecem nesse contexto entre eles têm como peça central um equilíbrio instável de poder . Como analisam Elias e Scotson (2000 p.23), “essa também é a pré-condição decisiva de qualquer estigmatização eficaz de um grupo outsider por um estabelecido. Um grupo só pode estigmatizar o outro com eficácia quando está bem instalado em posições de poder da quais o grupo estigmatizado é excluído".

E, não resta dúvida, mesmo integrando o grupo dos estabelecidos nas Engenharias, pois são profissionais formadas e atuantes no campo profissional, as mulheres constituem sua parcela mais outsider, mais vulnerável dentro do grupo de engenheiros e de estudantes de Engenharia, em que pese o número cada vez maior de alunas nas escolas e sua cada vez maior aceitação tanto nesses ambientes, como no mundo profissional.

No que tange ao ambiente profissional, por sua vez, pode-se afirmar que se as mulheres têm ousado outras especialidades além da Química e da Civil, continuam existindo lugares bastante delimitados para sua atuação, seja em termos de áreas de trabalho, seja no que diz respeito às atividades de trabalho propriamente ditas, ou ainda à sua posição nas hierarquias das empresas e instituições. As concepções de gênero presentes em algumas especialidades da Engenharia influenciaram as possibilidades de construção e de progressão na carreira profissional das engenheiras entrevistadas e, mesmo que aquelas concepções venham sofrendo modificações nos últimos 30 anos, a dinâmica da divisão sexual do trabalho tem se encarregado de restabelecer a ordem de gênero no interior do campo profissional, a cada novo nicho de trabalho que se abre nas engenharias. E as imagens 
e as concepções de gênero presentes na sociedade de uma forma geral e na profissão em particular, continuam exercendo seu papel simbólico, justificando aquela ordem: o feminino subordinado ao masculino.

Tomando o exemplo emblemático da Engenharia Civil, observa-se que, até hoje, o ambiente de obras parece "não combinar" muito com as engenheiras, e os argumentos utilizados nos discursos que tentam explicar o porquê da menor presença das mulheres nesses espaços profissionais são os tradicionais: o ambiente de obras abrutalhado e agressivo, o trabalho pesado e sujo, a falta de alojamentos e banheiros femininos, as longas caminhadas no mato em zonas distantes de centros urbanos etc. Do lado das mulheres, por sua vez, poucas "gostam" dessa atividade, a maioria prefere a área de projetos, planejamento; na obra elas declaram sentiremse observadas o tempo todo, além de o trabalho ser mais "confinado", limitando o contato com seus pares e de haver excessiva ênfase na prática em detrimento da teoria etc. Hoje em dia, contudo, esse espaço de trabalho está mais aberto às mulheres; mas se há um maior número de engenheiras nos canteiros de obras, internamente, a reprodução da divisão sexual do trabalho thes atribuiu preferencialmente atividades de gerenciamento do canteiro, como seleção de pessoal, compra de materiais etc. Elas raramente "tocam", são responsáveis pela obra, atribuição que continua masculina.

Se na construção civil as concepções de gênero e estereótipos femininos contribuíram em maior ou menor medida para o afastamento das engenheiras, o inverso parece ter acontecido numa nova área ou campo de trabalho que se desenvolveu a partir dos anos 80 , em torno da indústria dos softwares empresariais, a consultoria em Informática. Esse campo de trabalho parece ter sido particularmente importante para a absorção de engenheiros de produção de ambos os sexos, e especialmente, de mulheres. $\mathrm{Na}$ avaliação de um engenheiro entrevistado, a abertura desse novo campo de trabalho foi favorável ao ingresso das mulheres porque o trabalho de consultoria consiste em "ensinar' o pessoal da fábrica a usar o novo software, exige capacidade de relacionamento (competência "relacional"), saber ouvir, ter paciência, enfim, mobiliza saberes considerados inerentes à natureza feminina. Nesse caso, então, pode-se dizer que o balanço da concepções de gênero foi favorável às mulheres e as engenheiras souberam 
aproveitar a brecha autorizada pelos estereótipos e ocupar espaços no mercado. Mas a quantidade de trabalho mobilizada na função de consultoria entendida nos termos colocados acima , bem como sua importância para 0 resultado final de uma instituição, parece não ser adequadamente percebida e, conseqüentemente, valorizada. E nesse sentido, o trabalho dessas engenheiras, seguindo tradicional padrão verificado para o trabalho feminino tende a ser pouco visível e pouco reconhecido. Como afirma Danièle, engenheira francesa que trabalha em desenvolvimento de programas na área de prospecção de petróleo na França ,

“... o trabalho de suporte, ajuda, conselho, assistência, é invisível.... é um trabalho feminizado o de desenvolvimento de programas. Fica difícil ligar nosso trabalho a um resultado específico, pois está na base do desempenho geral da empresa... o que as mulheres fazem é organizar, tornar as coisas fáceis, coisas que também se faz em casa e isso é pouco valorizado ou não é considerado”.

Considerando a similaridade e a recorrência as relações sociais de sexo e das concepções de gênero que elas engendram nas sociedades ocidentais, pode-se afirmar que, também entre as engenheiras brasileiras, o trabalho de consultoria em informática, sua importância e complexidade tenderiam a ser pouco visíveis e valorizadas. Por isso mesmo caracterizado como um trabalho de mulher, uma boa colocação para uma engenheira.

\section{CONSIDERAÇÕES FINAIS}

Os anos 80 e os 90 foram tempos de mudanças para os engenheiros e para a Engenharia no Brasil, e essas mudanças provieram, tanto de importantes transformações ocorridas na economia e no mercado de trabalho brasileiros, como de alterações na composição interna do grupo profissional, provocadas pela democratização do sistema de ensino da Engenharia, pela acentuação da especialização da formação profissional e também pela maior presença de mulheres nas escolas de Engenharia, nas empresas e instituições. 
Amaior presença de mulheres nas Engenharias hoje, comparativamente há 30 anos atrás, trouxe modificações para a imagem que o próprio grupo faz de si e vem contribuindo para amenizar arraigados padrões de gênero presentes nas escolas de engenharia e nos ambientes de trabalho. Apesar disso, o grupo ainda hoje minoritário de mulheres se constitui em alvo de estigmatização por parte do grupo majoritário masculino. Os relatos das(os) entrevistadas(os) estão pontuados de situações e de expressões verbais que demonstram a discriminação de gênero de que as mulheres foram alvo durante suas trajetórias escolares e profissionais. Em geral, no ambiente escolar a discriminação se revelou por intermédio de mexericos depreciativos, piadinhas que objetivam intimidar as jovens.

Mesmo que nesse processo de transformação dos estereótipos de gênero presentes na engenharia caiam, algumas tradicionais barreiras ao ingresso das mulheres nos campos de conhecimento e de trabalhoe, ao mesmo tempo, se reproduza uma nova divisão sexual do trabalho internamente às especialidades, a configuração das relações de sexo no interior do grupo profissional está em movimento e parece favorável às mulheres. A própria ação das mulheres, portanto, vem contribuindo no decorrer do tempo para alterar essa configuração que favorece 0 sexo masculino, ocupando espaços dentro da área de conhecimento e da profissão e alterando a divisão sexual do trabalho instituída na área. Enfim, para as estudantes e profissionais , a perseverança e a resistência parecem ser a regra, a norma a ser seguida para a sua inclusão e permanência na engenharia.

\section{REFERÊNCIAS}

BRUSCHINI, Maria Cristina Aranha e LOMBARDI, Maria Rosa; "O trabalho da mulher brasileira nos primeiros anos da década de noventa". In: Anais do X Encontro Nacional de Estudos Populacionais, Caxambu, 7 a 11 de outubro, 1996; p. 483-516.

. "Mulheres e homens no mercado de trabalho brasileiro: um retrato dos anos 90". In MARUANI, Margareth;HIRATA, Helena As novas fronteiras da desigualdade. Homens e mulheres no mercado de trabalho. São Paulo, Senac, 2003, pp. 323-356. 
ELIAS, Norberto; Scotson, J.L. Os estabelecidos e os outsiders Sociologia das relações de poder a partir de uma pequena comunidade, Rio de Janeiro: Jorge Zahar , 2000.

FCC- Fundação Carlos Chagas. Banco de dados sobre o Trabalho das Mulheres; São Paulo, 1998 [ www.fcc.org.br/banco de dados/ bdmulher]; consulta em 8/8/2004.

GIANINNI, Mirella. "Ingegneri al feminile. Il contributo delle donne alla trasformazione del gruppo professionale”. In Anais do seminário CNRS/ Iresco 2002/2003 intitulado Les professions face aux mutations internationales. Les contributions récentes de la sociologie des groupes professionnels. Paris dezembro de 2003, pp.41-65 (mimeo).

GUEVARA, Patricia García. Genero y las profesiones no tradicionales: las ingenieras, IV Congresso da ALAST, Bloco temático 5 (Trabalho e Sociedade), tema $\mathrm{V}_{-}$(Identidades no trabalho), La Habana, Cuba, setembro 2003 (mimeo).

GUIMARÃES, Nadya Araújo; "Laboriosas mas redundantes: gênero e mobilidade no trabalho no Brasil dos 90". In Revista de Estudos Feministas, IFCS/UFRJ- CFH/UFSC, ano 9, 1/2001, Florianópolis, pp..83-102.

KÉRGOAT, Daniele. "La division de travail entre les sexes" In Kergoat, J. et al (orgs) Le monde du travail Paris, La Découverte 1998, pp.319327.

. "Division sexuelle du travail et rapports sociaux de sexe" In Hirata et al (orgs) Dictionnaire critique du féminisme. Paris, PUF, 2000, p.35-44 (Collection Politique d'aujourd'hui).

LOMBARDI, Maria Rosa. Perseverança e resistência: a engenharia como profissão feminina. Tese de doutoramento defendida em 17/2/2005 junto à Faculdade de Educação da UNICAMP- Universidade Estadual de Campinas; Campinas.

RODRIGUES, Maria de Lurdes. "As mulheres engenheiras em Portugal", in MATOS, Ana Cardoso e SILVA, Álvaro Ferreira da (orgs) Engenheiros 


$$
\text { revista tecnologia e sociedade }
$$

e engenharia em Portugal. Séculos XIX e XX. CIDEHUS/Colibri, Évora, 2004 (no prelo). 
